\title{
O BALÉ CLÁSSICO E A DANÇA CONTEMPORÂNEA NA FORMAÇÃO HUMANA: CAMINHOS PARA A EMANCIPAÇÃO*
}

\author{
Andréa Cristhina Rufino Assumpção **
}

\section{RESUMO}

Este artigo vem analisar, a partir de um estudo de caso comparativo entre o balé clássico e a dança contemporânea, como a dança se relaciona com a formação humana em uma sociedade capitalista hegemônica. Presenciamos na dança contemporânea formas muito ricas de trabalho, com uma grande abertura para o crescimento crítico e criativo do ser humano. Porém, estão presentes no grupo analisado algumas contradições no que se refere aos conteúdos e à metodologia utilizada para alcançar os objetivos. No balé clássico nos deparamos com a busca pela apropriação da técnica institucionalizada cujos significados e códigos refletem uma sociedade hierarquizada e autoritária. Sua proposta de trabalho é pautada na reprodução e repetição a fim de chegar a um movimento tecnicamente perfeito. Desvencilhar-se das antigas concepções reafirmadas pelo balé clássico sobre o ensino da dança é bastante árduo, porém muito necessário para que tenhamos uma nova proposta, pautada na liberdade e no respeito pela individualidade do ser humano. Acreditamos que também a possibilidade de criação, intervenção e questionamentos no espaço de ensino venha a ser fundamental para a formação de um ser humano que se entenda como sujeito de suas ações na sociedade em que está inserido.

PALAVRAS-CHAVE: Dança - Formação humana - Balé clássico - Dança contemporânea.

* Resumo da monografia apresentada como requisito para a conclusão do curso de Licenciatura em Educação Física da Universidade Federal do Paraná, no ano de 2002, sob a orientação da Professora Ms. Astrid Baecker Avila.

** Integrante do Programa de Pós-Graduação do Setor de Educação da Universidade Federal do Paraná. 


\section{INTRODUÇÃO}

Dance como uma flor que não pede licença para nascer.

(Kazuo Ohno)

A gente pergunta e pergunta, mas nunca o suficiente. A gente dança e dança, mas a expressão encontra seus limites.

(Hijikata)

Considerando o modo de vida da sociedade capitalista, percebe mos o pouco conhecimento que o homem atual detém sobre si próprio, atuando quase como máquina que (re)produz para (sobre/ sub)viver e (sobre/sub)vive para (re)produzir e esquecendo-se da condição de Ser humano. ${ }^{1}$

Deparamo-nos com uma engrenagem capitalista que pretende nos dominar e comandar, sugerindo a cada minuto como devemos nos vestir, morar, trabalhar e até nos mover. Isso nos induz a esquecer, portanto, de que podemos fazer opções e construir nossa própria história, e de que possuímos sentimentos e emoções que precisam ser considerados/expressados.

Diante dessa realidade, constatamos a existência de uma sociedade com idéias solidificadas, relutante em aceitar transformações e considerar diferenças; um mundo onde impera a hegemonia das formas, dos gostos e das opiniões. Porém, inseridos nessa sociedade, há grupos organizados que buscam a transformação e a superação da hegemonia.

Essas formas distintas de estar presente em uma mesma realidade nos são perceptíveis à medida que observamos as manifestações socioculturais de cunho popular e/ou erudito. As manifestações artísticas e culturais estão histórica e socialmente ligadas às formas de organização social em que foram produzidas.

Sendo assim, pretendemos com este estudo compreender a importância do ensino da dança como meio de formação humana, contrastando estas duas formas de manifestações dançantes: o balé clássico e a dança contemporânea; identificar as discussões que buscam conceituar essas modalidades e relacioná-las com a forma como vêm sendo desenvolvidos trabalhos nesta área; desvendar a metodologia de ensino utilizada em grupos de dança; analisar as conseqüências dessas metodologias na formação do ser humano 
que dança e verificar qual a participação crítica e criativa que os/as bailarinos/as têm como integrantes das respectivas companhias.

\section{O BALÉ CLÁSSICO: RESQUÍCIOS DE UMA HIERARQUIA SECULAR EM QUE IMPERAM CORPOS RÍGIDOS E MOLDADOS}

Acreditamos que todas as produções humanas/sociais, sejam elas científicas, artísticas, religiosas etc., devam ser disponíveis a todas as pessoas, independente de classe social, escolaridade, sexo ou etnia. Infelizmente percebemos, entretanto, que cada vez mais esses conhecimentos vêm sendo elitizados. Isso se torna claro, por exemplo, quando dirigimos nossos olhares para o balé clássico, uma modalidade de dança que surgiu nas cortes como entretenimento para os reis e que foi sendo cada vez mais elaborada através de um código técnico de passos e normas, chegando a vigorar atualmente como uma das modalidades mais praticadas e conhecidas.

Segundo Portinari (1989, p. 58), a dança teve seu primeiro tratado em Milão entre 1435 e 1436. Além de ter sido escrito para a nobreza, esse código criava diversas minúcias que só eram acessíveis ao entendimento dos mestres de dança; dificilmente classes menos providas tinham acesso a essa técnica ou espetáculo. A partir daí foram escritos novos documentos sobre a dança, e um deles conceituou o balletto, que passaria a designar um tipo de dança para ser realizada nas cortes renascentistas como entretenimento.

Ossona (1988, p. 73) comenta que no Renascimento o balé assumiu uma característica de espetáculo dançante, sendo apresentado em um teatro com uma platéia que habitualmente pagava por seu ingresso; foi quando nasceu o balé tal como o conhecemos hoje. Após quedas e renascenças surge, com Noverre (1727-1810), um período bastante eclético em suas possibilidades e, portanto, um conceito de arte teatral "despojada de maneirismo e uma busca da naturalidade, na medida em que ela obedeça ao conceito de imitação da natureza." Depois de Noverre, surge o coreodrama, com Viganó (1769-1821), variante esta que dava maior importância à emotividade e à plasticidade. 
Contradizendo essas duas vertentes naturalistas do balé, aparece o romantismo, que, com a estréia de Maria Taglione em La Silphide, coreografada por seu pai, Phillippe Taglione, promove uma supervalorização da mulher,

não em sua condição de mãe, esposa ou amante, mas como representação do inacessível, uma imagem do ideal sonhado pelo homem que está disposto a sacrificar sua vida por este ideal. [...] que imporá para sempre como a representação da bailarina clássica a imagem de uma mulher etérea, casta, envolta em véus brancos (o branco era o furor da época), coroada de flores, despojada de jóias rutilantes e sustentando-se sobre a ponta de um só pé, como se lhe custasse tomar contato com a terra. (Ossona, 1988, p. 73)

A partir daí, o papel que o bailarino (sexo masculino) assume em palco, grande parte das vezes atuando em $d u o s,{ }^{2}$ é apenas de "guindaste" para as bailarinas, a fim de que em seus reinos mágicos flutuem sobre a terra. Nessa época surgem também, com Marius Pepita (1822-1910), balés conhecidos como clássicos de repertório, como por exemplo, Copélia, Bela Adormecida e Lago dos Cisnes, os quais chegam até nós, nos dias de hoje, exatamente como foram criados. Segundo Ossona (1988, p. 74), nesse período os/as bailarinos/as perderam-se num virtuosismo exagerado, esquecendo-se da arte em si. Após, surgem Diaglev, Nijinsky e Fokine, que trazem um balé mais moderno, revigorando o balé masculino, unindo artes - música, teatro, dança -, caminhando para outras formas de dança e buscando um público mais ávido de novidades do que de sutilezas.

Porém, mesmo após o surgimento de outras escolas, o romantismo do balé clássico reina até os dias atuais, seguindo normas e regras, formando bailarinos e apresentando temáticas românticas e descontextualizadas da realidade social.

Ainda hoje, o balé clássico segue um código de normas que, seja ele francês, italiano ou russo, não perde a rigidez, chegando ao ponto de haver correções na angulação do rosto dos/as bailarinos/ as. Esses, pela hierarquia que aprenderam a obedecer desde muito cedo, permitem que modelem até mesmo seus rostos, expressões e olhares, ressaltando assim o processo de homogeinização social. Escolas de dança clássica só aceitam crianças menores de dez anos 
e que tenham um biotipo adequado, adotando como critérios de seleção os testes de flexibilidade e a aferição da estatura, do peso etc. O enredo e os temas de coreografias continuam sendo descontextualizados, e muitas vezes são apenas remontagens de peças apresentadas no início do século XX, os já comentados clássicos de repertório. Assim os/as bailarinos/as, inseridos/as em seus mundos encantados, com fadas, anjos e duendes, encantam e alienam pessoas, deixando-as desligadas de seus reais papéis sociais e insatisfeitas com suas vidas "humanas".

Diante dessas considerações e acreditando em um dança capaz de contribuir para a formação humana e para o desenvolvimento da expressão crítica e criativa é que no decorrer de séculos buscou-se uma nova forma de linguagem a partir da dança, dando origem ao que temos de mais recente hoje, a dança contemporânea.

\section{A DANÇA CONTEMPORÂNEA: UMA PROPOSTA... UM CAMINHO}

A arte contemporânea vem quebrando uma série de barreiras, ampliando suas fronteiras. O artista ganha uma maior liberdade de expressão, deixando de estar preso a esta ou àquela técnica, e o apreciador encontra uma abertura para participar, criar, e até mesmo exteriorizar suas interpretações e sensações. Para Benjamin, citado por Marques (1999, p. 24), "a obra de arte perdeu sua aura, não é mais única e eterna”. Na dança o panorama não difere muito.

A necessidade de inovar, de libertar-se de padrões e de expandir o cenário dançante é que leva artistas da dança, desde a década de 1960, a buscar novas formas de linguagem corporal, movimentos que vão de encontro ao retrato do mundo atual. Essa busca pelo novo tem dado aos artistas possibilidades de perceber em seus corpos novas sensações, novos movimentos, novas formas de linguagem. A liberdade do indivíduo para se expressar oralmente, de maneira espontânea, utilizando suas próprias experiências, suas próprias possibilidades e respeitando seu corpo e seus pensamentos, faz da dança contemporânea um grande passo para a emancipação desse indivíduo.

Paralelamente a essas novas descobertas e sensações surgem debates sobre a maneira de conceituar essa nova dança que emerge 
de nossos corpos a cada dia, questionamentos estes presentes no meio acadêmico, em encontros da área, nas academias, nos palcos. Essa é uma preocupação fundamental, pois afirmar que dança contemporânea seja isto ou aquilo limita e exclui novas possibilidades, novas linguagens e novas danças. Porém é preciso termos aqui um norte, uma referência do que possa ser essa dança.

Para Barnes, citado por Faro (1994, p. 124), “... a dança contemporânea é tudo aquilo que é feito neste tempo, por artistas que nele vivem". Para ele não importa o estilo, a procedência, nem os objetivos ou a forma a que se chegará. Faro ao citá-lo concorda com sua definição e afirma: "para ser contemporâneo, não se precisa forçosamente buscar estradas até então impenetradas. A dança, como arte e como diversão, já se diversificou de tal forma que sua contemporaneidade implica o hoje, mas não necessariamente o novo" (p. 124).

Consentino (1998, p. 51) compartilha da idéia de que contemporâneo é tudo o que é feito hoje, por artistas de hoje. Porém ela acredita que se deve usar de técnicas já criadas, de fontes já reconhecidas ou não e a partir delas fazer brotar a nova arte, diferentemente de Faro (1994, p. 124), que afirma não ser necessário buscar o novo e que demonstra em algumas colocações certa antipatia com o novo, com o inesperado.

Houve um espetáculo de balé-pintura, ou seja, bailarinos mergulhavam dentro de vasos de tinta e rolavam sobre imensos panos brancos ao som de uma mistura musical bastante indigesta, durante a qual só se podia pensar no tempo que levariam para tirar toda aquela tinta do corpo. Não havia ali qualquer coreógrafo e, no lugar de bailarinos, podiam ter sido usadas crianças ou macacos que o efeito teria sido absolutamente o mesmo. (Faro, 1994, p. 125)

Faro (1994) em sua colocação assume que o/a bailarino/a deve seguir certos códigos de movimento que busquem a "limpeza" destes e que de forma alguma movimentos tão rudimentares poderiam ser levados a palco. Sugere também que crianças com seus movimentos rudimentares não trariam beleza nenhuma aos olhos de quem assistisse a um espetáculo, enquanto Von Laban (1990, p. 55) afirma que "a essência desta forma contemporânea de movimento da dança 
é que cada indivíduo tem uma esfera na qual desenvolve seu próprio enfoque e utiliza sua própria interpretação".

Partindo da definição de Faro (1994) pode-se considerar contemporâneo tudo aquilo que é criado atualmente, seja ou não inovador. Mas o que se considera inovador? Qual é o parâmetro utilizado para dizer se isto é ou não é novo? Os grupos de axé e funk quando surgiram eram inovadores; podemos enquadrá-los então no que chamamos de dança contemporânea?

Emerge assim a grande ansiedade de se definir a dança contemporânea, mas diante da consciência de tal dificuldade é preciso e primário que se torne clara a diferença entre dança contemporânea e danças da contemporaneidade. Acreditamos que todas as danças realizadas atualmente por artistas ou não-artistas pertencem à contemporaneidade, porém não são necessariamente dança contemporânea.

\section{DANÇA CONTEMPORÂNEA}

Para melhor entendermos este contexto dançante, observamos dois grupos de dança, um de balé clássico e outro de dança contemporânea, ambos inseridos em uma mesma realidade social: Curitiba, Paraná, 2002.

Nos encontros da companhia de dança contemporânea analisada, o G2, percebemos que a dança está intimamente ligada à idéia de reencontro e descoberta. Nas aulas o aluno tem espaço para se expressar de maneira individualizada, considerando que o ritmo e a forma de realizar o exercício, mesmo que muito bem orientados, nascem de cada um. Algumas vezes se propõem duplas, outras vezes trios ou grupos maiores, o que permite ao indivíduo vencer barreiras impostas pelo meio social e percebê-las de maneira diferente daquela como eram percebidas antes.

As possibilidades propostas nas aulas vêm de encontro às necessidades do aluno, e, como os bailarinos do G2 vieram de uma carreira clássica, o importante é dar tempo para que eles se libertem dos códigos que estão presentes em seus corpos. Esse respeito com a individualidade de cada integrante ocorre desde a escolha dos exercícios propostos até à maneira de encaminhá-los, mostrando haver uma grande consideração com o ritmo e as dificuldades de 
cada bailarino/a, na tentativa de ajudá-los a superá-las através de seu entendimento e de sua descoberta.

Porém, apesar de o grupo buscar esse tempo para se desvencilhar das amarras clássicas, deparamo-nos com uma enorme contradição dentro dele. Os alunos continuam enraizados na necessidade de realizar pliés ${ }^{3}$ mais vezes por semana quando era de se esperar uma preocupação maior com novas formas de movimento: o grupo tem três aulas de clássico por semana e apenas duas de contemporâneo. Tudo isso em busca de uma técnica dita como base para se dançar. Questionamos a real necessidade dessa técnica, e muitas vezes desejamos negá-la; porém, será que esses bailarinos teriam um amplo repertório de movimentos e a facilidade de criar novas formas de executá-los se não possuíssem de forma tão enraizada as técnicas do balé clássico? Hoje, segundo Marques (1999, p. 67), o balé clássico torna a ser visto como a base para a dança, pois sua rigidez e disciplina preparam o/a bailarino/a para qualquer idéia de qualquer coreógrafo contemporâneo.

Nem é preciso dizer que com isso não raramente é reestruturada a hierarquia no mundo da dança, reforçando-se o eurocentrismo e o etnocentrismo em relação àquilo que pode ser considerado 'boa dança' . Esta tentativa de resgatar a técnica codificada pelo balé clássico poderia ser entendida como um eco restaurador de idéias e conceitos outrora valorizados e hoje novamente idealizados, a fim de estabilizar o instável, periodicizar o efêmero, regrar o indeterminado, unificar o múltiplo. O ensino do balé como base [grifo do autor] traz consigo resquícios e marcas, valores e significados [...] representando (ou voltando a representar) um ideal fortemente enraizado de ensino, de corpo, de mulher e de Arte [...]. Um corpo preparado, treinado, concebido e modelado [...]. (Marques, 1999, p. 67)

A nova técnica de dança proposta por Von Laban (1990, p. 16) e aplicada na dança moderna, vindo impulsionar o surgimento de um novo conceito na dança, estimula o emergir do movimento a partir de aspectos corporais e mentais, tornando-o uma ação consciente, e não apenas um refazer de passos aprendidos. A criação de movimentos não deixa de ser uma técnica de dança a partir do momento em que ela é sistematizada e consegue ser repetida pelo/a 
bailarino/a que a inventou e repassada para outros, o que gera um leque de possibilidades muito maior do que a simples reprodução de passos já criados.

Em aulas de dança, seja ela para profissionais ou amadores, seja na academia, em um corpo de baile ou em uma escola, a abertura para a criação é um ponto fundamental na formação de pessoas. Permite-lhes ir além dos conhecimentos elaborados pela humanidade como verdades absolutas e imutáveis, refletindo e interferindo sobre esses conhecimentos, reelaborando-os. (Fiamoncini \& Saraiva, 1999, p. 98)

Observamos que as aulas não se prendem à técnica institucionalizada, embora tenhamos percebido na execução dos exercícios de improvisação movimentos muito limpos e claros, realizados com grande precisão e qualidade técnica - o que talvez seja proveniente das aulas de clássico e que nos dá a impressão de deixar os bailarinos muito à vontade. Numa das aulas, porém, durante uma conversa ao final do exercício, os bailarinos expuseram a sua grande dificuldade de se movimentar, quase que instintivamente, sob algumas orientações dadas pela professora, questionando-a a respeito da valia desse tipo de exercício. Podemos afirmar que essa dificuldade de criar se origina de anos de reprodução dentro do balé clássico, à qual a maioria dos bailarinos foi submetida. Tal reprodução impede a possibilidade de criar, que traz para os bailarinos/as a satisfação e a liberdade de expressão.

A improvisação deve ter um espaço amplo nas aulas, pois o contato com suas próprias idéias, a necessidade e o estímulo para criar prepara e modifica diante do mundo o indivíduo que dança. Porém, poucos bailarinos têm a consciência de que o trabalho corporal de pesquisa de movimento e de concepção coreográfica poderia estar sendo expandido para atingir uma consciência social - focamos aqui a arte como um meio de comunicação e formação do artista e do espectador/apreciador. Observamos que, por mais que essa consciência exista, o assunto não é exposto para o grupo, talvez por se tratar de um grupo profissional em que a busca pela qualidade de movimento - mesmo que por caminhos diferentes daqueles do balé clássico - atropela essas discussões. Outro aspecto que talvez seja responsável pela não-discussão desses assuntos 
dentro do grupo pode ser a origem social de seus integrantes. Sua realidade social menos privilegiada dificulta o aprofundamento em discussões, já que esta realidade não se torna concreta à medida que surgem dentro do grupo debates sobre a consciência social. Este é o caso, por exemplo, do último trabalho da companhia, no qual poderia ter sido dado um enfoque maior para a questão do operário, o que não aconteceu - a questão passou quase despercebida desde a construção até o resultado final do trabalho.

Há ainda um fator que distancia o grupo das questões sociais mais profundas. São as questões de hierarquia postas dentro da instituição, já que o grupo está inserido em um órgão público. Bailarinos/as comentam que por mais que surjam idéias e projetos estes são sufocados, pois não há o interesse do governo em proporcionar espaços públicos de arte ou em discutir esses espaços. Sendo assim os trabalhos são expostos sempre no teatro, o que nos leva a considerá-lo como um meio elitizador da arte, quando era de se esperar o contrário. Pensamos que grupos como esse tinham o dever de proporcionar espaços culturais abertos para que o público sem acesso ao teatro, por diversas questões socioculturais, pudesse ter contato com esse mundo da arte tão necessário para o desenvolvimento social.

Felizmente, mesmo não atingindo a sociedade de forma geral, e ainda tendo muito para caminhar nesse sentido, o trabalho do grupo é enriquecedor para os que podem partilhar de tantas descobertas espectadores, bailarinos, professores etc. Os trabalhos coreográficos levados ao palco têm um grande papel nessa caminhada, e é por isso que lutamos e acreditamos na democratização desse espaço.

As concepções dos trabalhos levados a palco são geralmente realizadas por pessoas convidadas, algumas vezes pelos bailarinos e, outras vezes, pela própria diretora. Porém, o processo de criação de movimentos quase sempre é feito pelos próprios bailarinos. Já houve espetáculos em que a criação foi toda do coreógrafo, mas esse tipo de trabalho não vem de encontro à vontade do grupo, que criou, a partir do momento em que começou a trabalhar com dança contemporânea, uma necessidade de expressar idéias e pensamentos próprios.

Nesse aspecto os/as bailarinos/as da companhia trabalham com pesquisa de movimento, sendo intérpretes-criadores, até chegar ao 
resultado final do trabalho. Mesmo depois da estréia podem ocorrer modificações propostas pelos próprios intérpretes.

A participação do/a bailarino/a no processo criador, desde a pesquisa de movimento até a discussão do tema, proporciona o seu crescimento, tornando-o mais criativo, autônomo, consciente do seu corpo e de sua realidade. Além da formação humana, esse processo acarreta uma satisfação na execução do trabalho, o que engrandece a qualidade estética da dança que se constrói, pois o corpo deixa de ser objeto e passa a ser sujeito. Afinal cada um é esse corpo e não apenas o tem.

A participação dos bailarinos é intensa em muitos dos processos, porém a consciência dessa participação ainda é meio restrita. Provavelmente eles ainda não perceberam a grande influência que têm, cada um com sua história de vida, na história da companhia.

Conseguimos captar alguns aspectos bastante presentes na realidade estudada: a liberdade para criar e expor opiniões, seja pela linguagem corporal e/ou oral; a importância e o respeito que se tem pela individualidade; a necessidade de desenvolver uma boa consciência corporal, evoluindo para uma consciência social; e o modo como a arte está inserida no entrelaçar dessa dança. Procuramos ainda desvendar outras faces do mundo da dança indo de encontro a uma realidade bastante diferente da dança contemporânea, porém inserida em uma mesma sociedade contemporânea: o balé clássico.

\section{O BALÉ CLÁSSICO}

A pesquisa sobre balé clássico foi realizada nas aulas do Grupo Iniciante e Intermediário de um estúdio de dança localizado, como dissemos, em Curitiba, Paraná.

A procura pelo balé clássico fundamenta-se na idéia de que essa modalidade é a base para as outras. As pessoas vão em busca da técnica e da disciplina corporal ofertada pelo balé e também do sonho de serem bailarinas. Essa técnica está incutida diretamente na maneira de conduzir as aulas, já que ela se torna o objetivo principal, e não apenas um conteúdo a ser trabalhado. A influência dessa técnica sobre a formação do indivíduo é indiscutível, pois, quando falamos em dança, nos referimos necessariamente a corpo, no seu 
sentido mais amplo - corpo que pensa, sente e age. Corpo atravessado por cultura, composto por diversas influências do meio em que está inserido, desde a forma de funcionamento orgânico até a de interação com o meio, pois o corpo - ou os corpos - está sendo constantemente criado/estruturado/construído; destruído/desestruturado/desconstruído; recriado/reconstruído/reestruturado de acordo com valores, padrões, ideologias, perspectivas sociais, estéticas e políticas, coletivas ou individuais (Dantas, 1999, p. 32). Tudo nesse corpo é construído e modificado, desde a sua forma de falar, vestir, pensar, alimentar-se, mover-se, comunicar-se com o mundo. Tais formas e costumes são criados e recriados pelas sociedades no decorrer do tempo e do espaço, sendo passados de geração em geração. Nas aulas, por exemplo, há pouca abertura para a intervenção dos alunos/as, e isso não se justifica no objetivo dessas aulas, mas sim na metodologia historicamente construída para esse estilo de dança, em que a professora não se questiona sobre isso. Já em outros grupos, inclusive profissionais - utilizando o exemplo da dança contemporânea -, essa abertura para idéias e conversas faz parte do crescimento e do objetivo coletivo.

Segundo Aristóteles, citado por Dantas (1999, p. 30), a maneira de realizar certas atividades é construída a partir de experiências individuais, quando se descobre o como (saber experimental), o porquê (conhecimento das causas) e o fazer (criativo, poético). Dessas experiências surge a techne, ${ }^{4}$ que passa a ser um conhecimento possível de ser ensinado. Esse processo de invenção do modo de fazer pode ser constantemente reinventado, de modo a se recriar a técnica.

Para Mauss, citado por Avila (2000, p. 5), técnica corporal significa "as maneiras com que os homens, sociedade por sociedade e de maneira tradicional, sabem servir-se de seus corpos". Para ele cada sociedade possui hábitos corporais diferentes, que só se tornam possíveis de avaliar analisados por um tripé entre a fisiologia, a psicologia e a sociologia. Assim ele afirma que a forma de nos portar diante de determinadas situações varia de cultura para cultura, pois a maneira de utilizar o corpo é aprendida através da imitação de técnicas corporais que podem ser modificadas ou não quando passam de geração para geração. Porém as maneiras de se mover são sempre resultantes de um conjunto de valores apreendidos socialmente; as técnicas corporais uti- 
lizadas dia a dia são resultantes de um processo social e igualmente estão repletas de códigos e significados que vão desde a maneira ereta de se portar, até a forma de andar, correr e gesticular.

Esse corpo sujeito a modificações é também o corpo que dança e que busca constantemente modos de se mover, criando uma técnica, "uma maneira de realizar os movimentos e de organizá-los, segundo as intenções formativas de quem dança" (Dantas, 1999, p. 31). Se essa técnica é recheada de intenções, o movimento humano é história e retrato social, desde as intenções que o provocam até as intenções que este irá provocar depois de realizado.

O movimento no corpo que dança a transitoriedade é traço que deixa marcas; impulso e contenção; é velocidade e lentidão; é imobilidade e ação. O movimento é matéria-prima da dança, visto que a torna real ao conferir a ela visibilidade.(Dantas, 1999, p. 30)

Para Von Laban (1990, p. 16) a técnica tradicional da dança envolve o domínio dos movimentos individuais para cada modalidade específica, como o balé, as danças folclóricas e as de salão. Essa técnica é ensinada de maneira fiel e sem grandes modificações, principalmente se no seu processo de ensino há objetivos que a tornam rígida e concreta. Diferentemente das danças populares, folclóricas ou de salão - que sofrem pequenas modificações por serem passadas com fim único na socialização de uma cultura -, o balé clássico mantém sua forma sistematizada sem permitir alterações em sua execução. É por isso que nos deparamos com um método de aula tão rígido e calcado em valores muitas vezes já superados em discussões e experiências.

Nas aulas observadas todos os exercícios são realizados primeiramente pela professora, de forma completa, havendo nessa demonstração uma relação hierárquica entre professor e aluno na qual o professor se apresenta como detentor do conhecimento, e o/a aluno/a apenas como receptor/a de algo que já está completamente construído e acabado. Ao final da demonstração a professora realiza a sequiência novamente, agora com o acompanhamento dos/as alunos/as e com o som da sua voz contando os oito tempos de maneira ritmada. Explica alguns detalhes do exercício, como a direção do olhar, o alongamento de joelhos e braços, entre outros. Só então os/as bailarinos/as realizam o exercício, muitas vezes 
bastante confusos por não terem absorvido com perfeição técnica a execução deste ou daquele movimento. Essa maneira de encaminhar as aulas traz para o aluno uma insatisfação com sua forma de mover-se, pois toda vez que não se adapta ao exercício passa a acreditar que seu corpo está incorreto. Isso exige dele uma disciplina que o faz calar-se diante das dificuldades e vencê-las apenas porque tem de ser assim, e não por entender o porquê de tal dificuldade e se realmente deseja se formatar a este ou àquele padrão.

O método utilizado nas aulas não permite questionamentos por não se apresentar flexível a novas propostas. $\mathrm{O}$ aprendizado ocorre por demonstração e repetição, até alcançar o resultado ótimo. As aulas são planejadas para caber perfeitamente dentro das músicas clássicas divididas em oito tempos. Tais músicas são utilizadas em todas as aulas sem exceção, numa sequiência de exercícios determi-nada pelos "tratados do balé clássico", ensinados pelo mesmo método há vários anos. A participação dos/as bailarinos/as nas aulas limita-se à boa execução dos exercícios e das coreografias, tragos prontos pela professora.

A boa postura, o bom comportamento, as boas maneiras são tão valorizadas em nossa sociedade, que a busca pelo balé clássico baseia-se nessas qualificações, reforçadas pela rigidez da técnica e pela exacerbação da disciplina corporal.

Essa disciplina exigida durante ensaios e a produção dentro das aulas estão sendo buscadas, entretanto, por um caminho que possibilite ao indivíduo escutar seu corpo e suas vontades? Ou quando falamos em disciplina em uma aula de dança nos referimos a aceitar o que o corpo não aceita, calar quando se gritam as diferenças, reproduzir quando se quer criar? Muitas vezes a busca pela perfeição traz apenas a repetição de movimentos aprendidos em um espaço que priva o/a bailarino/a de experimentar novas possibilidades, descobrir novas técnicas; ou seja, buscar novos caminhos para atingir um resultado semelhante a outro, porém cheio de prazer e novidades.

A auto-estima e a disciplina conquistadas em aulas serão usadas para se alcançar um resultado ótimo que será exposto em espaços de apresentação, geralmente pagos. A exemplo a própria instituição, no período da visita, estava organizando uma mostra paga, em um teatro localizado dentro de um shopping. Segundo a professora, a instituição nunca realizou mostras em espaços públicos. 
Cabe, portanto, perguntar: para quem estamos fazendo arte? Sabemos realmente em que sociedade estamos inseridos e que dança queremos dançar? Para a professora do grupo observado o papel social da dança é muito claro. Ela afirma que durante as aulas esquecemos nossos problemas e nos tornamos pessoas mais felizes. Sendo assim, nos interpelamos: que tipo de seres humanos estamos formando, instigando-os a esquecerem seus problemas em vez de questionálos e procurar resolvê-los?

Formamos pessoas que aceitam tudo como está e se contentam com o pouco que recebem, pronto e estagnado. Afirmamos isso baseados no fato de que os/as alunos/as não demonstram nenhum desejo de criar nem de participar mais das aulas com suas idéias e opiniões. A composição coreográfica, assim como a aula, é toda de autoria da professora, desde o tema até os movimentos, as músicas, os figurinos. Todo ano é preciso montar um trabalho, que será construído de acordo com o seu objetivo final - competição, mostra, entre outros. O tema nem sempre está presente, e, quando está, é pesquisado apenas pela coreógrafa, que explica sobre ele para os/as bailarinos/as. Dessas aulas e concepções nascem opiniões bastante variadas sobre o papel social da dança.

As alunas falam sobre socialização, e logo em seguida a relacionam com consciência corporal e melhor postura; ou seja, nos deparamos com uma socialização pautada em códigos rígidos de boa postura e de educação corporal com a finalidade de moldar um cidadão dócil, que aceita sem questionar, às vezes, sem perceber as contradições do dia-a-dia. Defrontamo-nos com a idéia de que a dança é uma expressão de sentimentos, porém, dentro do contexto observado, todos dançam expressando o sentimento de apenas um: a professora, já que todo o trabalho é construído por ela. Será que é esta arte que buscamos, a arte da reprodução?

Percebemos o balé clássico como uma página necessária para a história da dança, mas os fatos considerados mostram que muitos dos seus valores devem ser rediscutidos e repensados a fim de formarmos cidadãos emancipados, capazes de realizar escolhas perante as portas abertas pela vida. 


\section{EM BUSCA DE RESPOSTAS... APENAS UM QUESTIONAMENTO A MAIS}

A dança, inserida em uma sociedade ocidental capitalista, apresenta fortes raízes de hierarquia e disciplina mesmo quando surgem, expressas nas pedagogias do corpo, propostas de superação desses valores. Elementos como a valorização e a necessidade da técnica institucionalizada estão presentes nas propostas mais inovadoras de dança, fomentando questionamentos sobre a real relevância dessa técnica.

Cabe alertar, entretanto, para a conveniência de se pensar em uma dança cuja base seja a criação de uma técnica própria; ou seja, em que somente a partir do aprofundamento se dê a apropriação da técnica já institucionalizada. Vale ressaltar a importância de uma aula em que a participação do/a bailarino/a seja intensa, em que ele/ a expresse seus desejos e limites e troque experiências. Não se deve excluir o fato de que estamos inseridos em uma coletividade, e esse aprendizado pode resultar de vivências coletivas e/ou da observação e execução de movimentos tradicionalmente realizados por determinados grupos, sem que ninguém precise, entretanto, deter-se a ensinar passos de dança. Do mesmo modo, pode-se criar técnicas pessoais, que reinventarão gestos, passos e movimentos, propiciando um modo particular de dançar. Mas certamente tais técnicas estarão ligadas, de alguma maneira, às experiências do ser humano na sociedade (Dantas, 1999, p. 33).

Desse modo, devemos perceber quais os caminhos tomados para o aprendizado em dança, considerando as experiências apreendidas fora do espaço da aula, pois afinal estas estão também construindo esse corpo dançante.

Reafirmamos ainda a importância de possibilitar espaços de criação e exposição de idéias próprias de cada aluno/a, uma vez que a chave para a emancipação do indivíduo está na forma como ele é incentivado diante das questões do mundo que o cerca. E esse incentivo deve estar presente em todos os espaços onde ele é orientado para agir de diferentes formas, sendo sujeito de sua história.

Vale relembrar, também, com relação aos dois grupos, a relevância de fomentar discussões em torno de assuntos que surgem 
em sala e muitas vezes passam despercebidos. É preciso cavar dúvidas para que se busquem respostas próprias e inovadoras.

Reconhecemos como a chave para nosso objetivo - a emancipação do ser humano - uma dança viva, que não aliene e nem sufoque, mas que dance a vida em sua totalidade, como ela é.

\title{
Classic Ballet and Contemporary Dance in Human Development: Paths to Freedom
}

\begin{abstract}
This article aims at analizing, from the starting point of a case study comparing Classic Ballet and Contemporary Dance, how dance can relate to human development, within the context of a capitalist-dominated society. We have observed that contemporary dance offers many enriching forms of work, with great openness for the perceptive and creative growth of a human being. The analyzed group, however, presented a few contradictions in regards to the contents and methodology that were used to achieve their goals. Lettin go of the old conceptions in the teaching of dance, wich are very much reaffirmed in classic ballet, is hard to achieve. It is, however, absolutely necessary, if we are to adopt a new approach, based on freedom and respect for human individuality. Classic ballet searches for the appropriate, institutionalized technique, which brings in itself codes and meanings that reflect an authoritative and hierarchical society. Its work is based on reproduction and repetition in order to achieve technically perfect movements.I believe that the possibility of creation, intervention and questionings within the teaching environment are fundamental to the upbringing of a human being who understands him/herself as the creator, the author of his/her own actions within society.
\end{abstract}

KEY WORDS: Dance - Human development - Classic ballet - Contemporary dance.

\section{El Ballet Clásico y la Danza Contemporánea en la Formación Humana: Caminos para la Emancipación}

\section{RESUMEN}

Este artículo analiza, a partir de un estudio de caso comparativo entre el Ballet Clásico y la Danza Contemporanea, cómo la danza se relaciona con la formación humana, injerida en una sociedad capitalista hegemónica. Presenciamos en la Danza Contemporánea formas muy ricas de trabajo, con una gran abertura para el crecimiento crítico y creativo del ser humano. Sin embargo, están presentes en el grupo analizado, algunas contradicciones relacionado a los contenidos y a la metodología utilizada para alcanzar los objetivos. Desvencijarse de las antiguas concepciones de enseñanza de la danza, reafirmadas por el ballet clásico es bastante árduo, pero muy necesario para que tengamos una nueva propuesta, determinada en la libertad y en el respeto por la individualidad del ser humano. En el Ballet Clásico nos ponemos ante la búsqueda de la apropiación de la técnica institucionalizada que carga consigo significados y códigos que reflejan una sociedad hierarquizada y autoritaria, la propuesta del trabajo es determinada en la reproducción y 
repetición con el fin de llegar a un movimiento técnicamente perfecto. Creo que la posibilidad de creación, intervención y cuestionamientos en el espacio de enseñanza viene a ser fundamental para la formación de un ser humano que se entienda como sujeto de sus acciones injerido en una sociedad.

PALABRAS CLAVES: Danza - Formación humana - Ballet clásico - Danza contemporánea.

\section{NOTAS}

1 Entende-se que a condição de Ser humano diz respeito à dignidade na vida física, social e psicológica, o que abrange a capacidade, o direito e a necessidade de expressar idéias e de escolher diante de situações diversas.

2 Coreografia dançada por apenas um homem e uma mulher.

3 Passo de balé clássico francês em que se flexionam os joelhos seguindo o alinhamento dos pés. O termo está sendo utilizado aqui como uma referência à técnica codificada desse estilo de dança.

4 Termo grego que designa ofício, habilidade, arte (Dantas, 1999, p. 30).

\section{REFERÊNCIAS}

AVILA, A. B. As relações entre cultura e subculturas: circunscrevendo a cultura corporal. 2000. Dissertação (Mestrado em Educação Física) - Centro de Educação Física e Desportos, Universidade Federal de Santa Catarina, Florianópolis, 2000.

CONSENTINO, M. T. de F. A dança moderna e a dança contemporânea em Curitiba. 1998. Monografia (Especialização em Fundamentos Estéticos de Ensino da Arte) - FAP, Curitiba, 1998.

DANTAS, M. Dança, o enigma do movimento. Porto Alegre: Editora da UFRGS, 1999.

FARO, A. J. Pequena história da dança. Rio de Janeiro: Nova Fronteira, 1994.

FIAMONCINI, L.; SARAIVA, M.C. Dança na escola: a criação e a co-educação em pauta. In: KUNZ, E. (Org.). Didática da Educação Física 1. Ijuí: Unijuí, 1999. 
OSSANA, Paulina. A educação pela dança. São Paulo: Summus, 1988.

MARQUES, I. A. Ensino da dança hoje: textos e contextos. 2. ed. São Paulo: Cortez, 1999.

PORTINARI, M. História da dança. Rio de Janeiro: Nova Fronteira, 1989.

VON LABAN, R. Dança educativa moderna. São Paulo: Ícone,1990.

Recebido: maio de 2003 Aprovado: junho de 2003

Endereço para correspondência Andréa Cristhina Rufino Assumpção Rua Orestes Beltrani, $n^{\circ}$ 116, Bom Retiro Curitiba - PR CEP: 82120-03 
